\title{
A novel unanticipated type of pseudouridine synthase with homologs in bacteria, archaea, and eukarya
}

\author{
YUSUF KAYA and JAMES OFENGAND \\ Department of Biochemistry and Molecular Biology, University of Miami School of Medicine, Miami, Florida 33101, USA
}

\begin{abstract}
Putative pseudouridine synthase genes are members of a class consisting of four subgroups that possess characteristic amino acid sequence motifs. These genes have been found in all organisms sequenced to date. In Escherichia coli, 10 such genes have been identified, and the $\mathbf{1 0}$ synthase gene products have been shown to function in making all of the pseudouridines found in tRNA and ribosomal RNA except for tRNA ${ }^{\text {Glu }}$ pseudouridine13. In this work, a protein able to make this pseudouridine was purified by standard biochemical procedures. Amino-terminal sequencing of the isolated protein identified the synthase as $\mathrm{YgbO}$. Deletion of the $y g b O$ gene caused the loss of $\mathrm{tRNA}{ }^{\text {Glu }}$ pseudouridine13 and plasmid-borne restoration of the structural gene restored pseudouridine13. Reaction of the overexpressed gene product, renamed TruD, with a tRNA Glu transcript made in vitro also yielded only pseudouridine13. A search of the database detected 58 homologs of TruD spanning all three phylogenetic domains, including ancient organisms. Thus, we have identified a new wide-spread class of pseudouridine synthase with no sequence homology to the previously known four subgroups. The only completely conserved sequence motif in all $\mathbf{5 9}$ organisms that contained aspartate was GXKD, in motif II. This aspartate was essential for in vitro activity.
\end{abstract}

Keywords: Glutamate tRNA; pseudouridine13; TruD; Escherichia coli

\section{INTRODUCTION}

Pseudouridine (5-ribosyluracil; $\Psi$ ), is the most common modified nucleoside found in RNA (Rozenski et al. 1999). It is made by isomerization of selected uridines in a preformed polynucleotide by a set of enzymes called $\Psi$ synthases. No energy input is required for the reaction, and no cofactors are involved, except that zinc is essential for a yeast synthase (Arluison et al. 1998) and in eukaryotes, $\Psi$ formation in ribosomal RNA requires the participation of at least three auxiliary proteins and a guide RNA (Kiss 2001). The enzymes are specific for particular uridines in an RNA and also for the RNA species. Commonly, each $\Psi$ in an RNA is made by its own synthase, but there are a number of cases known in which a single synthase makes more than one $\Psi$ (Kammen et al. 1988; Conrad et al. 1998; Huang et al. 1998a; Lecointe et al. 1998; Motorin et al. 1998; Raychaudhuri et al. 1998; Chen and Patton 1999, 2000; Hellmuth et al. 2000). The reverse, more than one synthase

Reprint requests to: Dr. James Ofengand, Department of Biochemistry and Molecular Biology (R-629), University of Miami School of Medicine, P.O. Box 016129, Miami, FL 33101, USA; e-mail: jofengan@molbio.med. miami.edu.

Article and publication are at http://www.rnajournal.org/cgi/doi/ 10.1261/rna.5230603. making the same $\Psi$, has so far not been found. Typically, $\Psi$ synthases are specific for a single class of RNA, but rare exceptions to this rule also exist (Wrzesinski et al. 1995b; Massenet et al. 1999).

As a result of this high specificity of $\Psi$ synthases and the frequent occurrence of $\Psi$ in tRNA, rRNA, and sn(o)RNA, multiple $\Psi$ synthases can be found in most cell types. For example, prior to this work, Escherichia coli was known to have 10 experimentally proven $\Psi$ synthases (Del Campo et al. 2001). The maximum number so far found in bacteria is 12, in Vibrio cholerae (Ofengand 2002) and in Xanthomonas species (J. Ofengand, unpubl.). The synthases in the above two organisms were not directly identified, but instead, putative synthase genes were identified by amino acid sequence homology with experimentally identified synthases (Gustaffson et al. 1996; Koonin 1996; Ofengand and Rudd 2000; Ofengand 2002). This technique is quite powerful, for example, 6 of the $10 \mathrm{E}$. coli synthases were predicted by this method and subsequently confirmed experimentally. By this approach, $\Psi$ synthase genes have been identified in all of the completely sequenced genomes from Bacteria, Archaea, and Eukarya that are publicly available (Ofengand 2002; J. Ofengand, unpubl.). Thus, all forms of life appear to have $\Psi$ synthases, and by extension should have $\Psi$ residues. This in turn implies a functional role for $\Psi$ that is both ancient and that crosses phyla boundaries. 
The number of $\Psi$ synthases in a given organism identified by this approach is quite variable. As noted above, $V$. cholerae and Xanthomonas sp. have 12 putative synthases. On the other hand, the Crenarchaeota so far sequenced, Aeropyrum pernix, Pyrobaculum aerophilum, Sulfolobus solfataricus, and Sulfolobus tokodaii have but a single synthase gene that is highly homologous to that for yeast Cbf5 and its equivalent in other eukaryotes. This is the $\Psi$ synthase believed to function in conjunction with guide RNAs to make $\Psi$ in ribosomal RNA of eukaryotes. This result, on the one hand, implies that guide RNAs are used in these archaeal organisms, but, on the other hand, raises the question of where is (are) the synthase(s) for making $\Psi$ in their tRNA. Although it is not known experimentally whether $\Psi$ is present in the tRNA of these organisms, it seems highly unlikely that $\Psi$ would be completely absent. One possibility is that there are $\Psi$ synthases remaining to be discovered that are not detectable by the homology searches used up to now because their amino acid sequences are truly distinct. A hint that such a possibility could occur comes from the X-ray structures of TruA (Foster et al. 2000), TruB (Hoang and Ferré-D’Amaré 2001), and RsuA (Sivaraman et al. 2002), which show considerable structural similarity including the position of the putative catalytic aspartate residue, despite the fact that the sequence of TruA is sufficiently different from the others so as to place TruA in a family separate from the TruB, RsuA, and RluA families (Ofengand and Rudd 2000), although it is still recognizable as a $\Psi$ synthase.

In E. coli, although the function of all $10 \Psi$ synthases has now been assigned, no synthase for $\Psi 13$ of tRNA ${ }^{\text {Glu }}$ has yet been identified (Del Campo et al. 2001). Moreover, individual deletion of each of the 10 synthase genes failed to cause the loss of this $\Psi$ from tRNA ${ }^{\text {Glu }}$ (Y. Kaya, data not shown). We hypothesized that this synthase might have an amino acid sequence that is completely different from the $\Psi$ synthases known up to now and searched for it by the standard biochemical procedures we used previously to identify three other E. coli $\Psi$ synthases (Nurse et al. 1995; Wrzesinski et al., 1995a,b).

In this study, we identify the gene encoding the synthase that generates $\Psi 13$ of tRNA ${ }^{\text {Glu }}$. We show that although this protein has no amino acid sequence similarity to known $\Psi$ synthases, it is homologous to a new class of 58 proteins of previously unknown function whose genes are found in organisms from all phyla. Thus, this work defines at least one potential function for these proteins. Furthermore, as none of the known RNA-binding motifs can be detected among the six conserved motifs of this class of proteins, they should contain novel RNA-binding sequences. These sequences may identify other classes of RNA-binding proteins including, but not limited to, other RNA base-modifying enzymes. We also identify an essential aspartate residue found in a short sequence motif common to all members of this new class, but which is completely different from the essential aspartate-containing motif II of the known $\Psi$ synthases (Huang et al. 1998b; Ofengand et al. 2001b; Ofengand 2002). This new sequence motif is likely to be part of an alternative structural design for the catalytic center of $\Psi$ synthases. These observations expand our knowledge of the variety of $\Psi$ synthases, and may explain the apparent paucity of these enzymes in certain organisms.

\section{RESULTS}

\section{Purification of the $\Psi 13$-forming enzyme and identification of the gene}

Isolation of the $\Psi 13$-forming activity from E. coli was done by classical biochemical means. The only convenient quantitative assay for $\Psi$ formation is the release of ${ }^{3} \mathrm{H}$ from position 5 of uridine in the process of isomerization to $\Psi$ (Cortese et al. 1974). Because in E. coli, tRNA ${ }^{\text {Glu }}$ is the only tRNA with a $\Psi 13,5-\left[{ }^{3} \mathrm{H}\right]$ uridine-labeled transcripts of this gene were used to assay for activity. Moreover, as tRNA ${ }^{\text {Glu }}$ has two $\Psi$, at positions 13 and 55, the source of the cell-free extract was the $\Delta t r u B$ strain, which does not make $\Psi 55$ (Gutgsell et al. 2000). Therefore, aside from ${ }^{3} \mathrm{H}$ release due to other activities such as $\mathrm{m}^{5} \mathrm{U}$ formation, which requires S-adenosyl methionine, not included in the assay, ${ }^{3} \mathrm{H}$ release activity should be indicative of $\Psi 13$ formation. A purification procedure previously used successfully for other E. coli $\Psi$ synthases (Nurse et al. 1995; Wrzesinski et al. 1995a,b) was adopted. The final step of the purification is shown in Figure 1. A single peak of activity was obtained that correlated well with a major protein band at $\sim 40 \mathrm{kD}$. This is only slightly larger than that found for other $\Psi$ synthases (Del Campo et al. 2001). Amino-terminal sequencing of this band yielded the sequence MIEFDNLTYL, an exact match only to the predicted product of the E. coli $y g b O$ gene. The calculated MW, $39.1 \mathrm{kD}$, is in good agreement with that for the protein band on SDS gels (Fig. 1B). Proof that the $y g b O$ gene product is solely responsible for $\Psi 13$ formation was obtained by deletion of the gene.

\section{$\Psi$ sequencing analysis of a $y g b O$ deletion strain}

The $y g b O$ gene was deleted by the method of Datsenko and Wanner (2000). Deletion was verified by kanamycin resistance, and the increased size of the PCR product produced by amplification from the amino- and carboxy-terminal ends of the gene (data not shown). Deletion had no obvious effect on growth. To be sure that the deletion strain as isolated was not a pseudorevertant with normal growth properties, it was backcrossed to wild type by $\mathrm{P} 1$ transduction. Of 88 kanamycin-resistant colonies obtained, none showed a smaller colony phenotype. Therefore, if a secondsite mutation to produce a wild-type colony phenotype existed, it must cotransduce at a frequency $>98.9 \%$, which means it must be within 350 bp of the truD gene (Bachman et al. 1976). Analysis of tRNA Glu from this deletion strain 
A

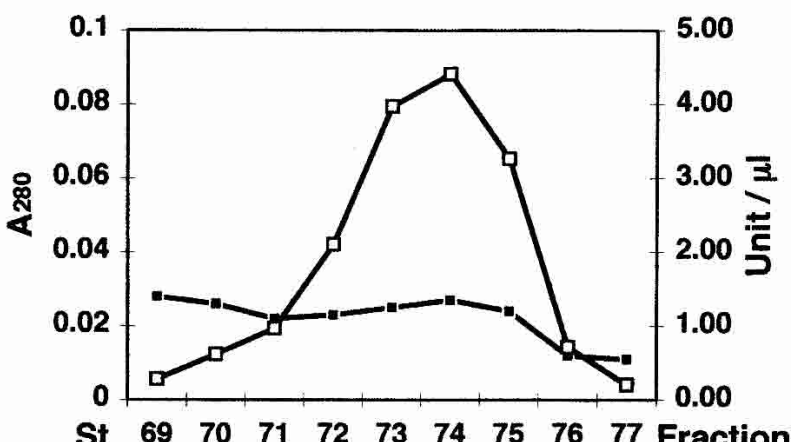

B

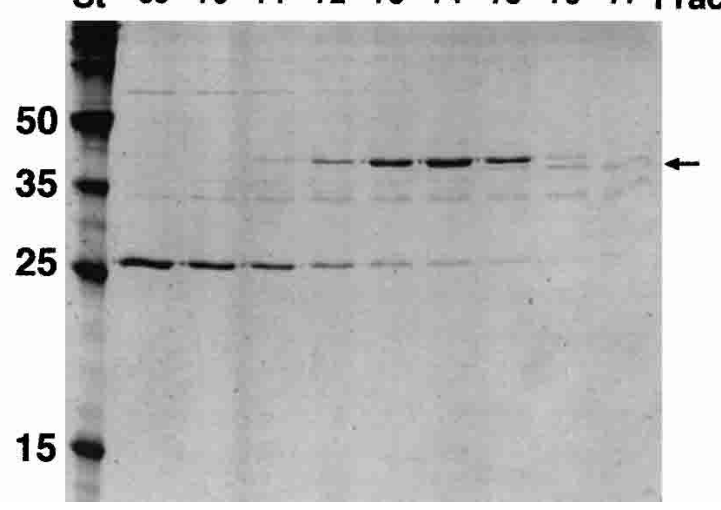

FIGURE 1. MonoS column purification of tRNA ${ }^{\text {Glu }} \Psi 13$ synthase. (A) Activity $(\square)$ was tested as described in Materials and Methods and units were expressed as described. Protein was measured as $A_{280}(\boldsymbol{\square})$. (B) Equal volumes of the column fractions indicated were electrophoresed in SDS gels. (St) MW standards with values as indicated. (Arrow) protein band taken for sequencing.

and the wild-type control showed that $\Psi 13$, present in the wild type, was absent from the deletion strain (Fig. 2). Both strains were transformed with $\mathrm{p} \operatorname{Trc} 99 \mathrm{~A}$ as controls for the D80D pair of lanes in which pTrc99A carrying only the wild-type structural gene was used to transform the deletion strain. The $y g b O$ structural gene restored $\Psi 13$ formation (Fig. 2), showing that the $y g b O$ product is necessary and sufficient for $\Psi 13$ formation. Therefore, we have renamed YgbO as TruD, the fourth tRNA-specific $\Psi$ synthase.

\section{In vitro activity of overexpressed and affinity purified TruD}

To test the in vitro activity of TruD, the gene was subcloned into pET28a and overexpressed in BL23(DE3) cells. Good expression was obtained with $\sim 70 \%$ in the soluble phase. Because this construct places a His tag at the amino terminus of TruD, it was possible to purify it by affinity chromatography on a Ni-binding resin. The in vitro substrate used was a 5- $\left[{ }^{3} \mathrm{H}\right]$ uridine-labeled in vitro transcript of tRNA $^{\text {Glu }}$, so that $\Psi$ formation could be followed by ${ }^{3} \mathrm{H}$ release. As shown in Figure 3A, reaction occurred readily and reached a stable plateau at $\sim 1$ mole tritium released per mole of transcript added, exactly as expected. Addition of more enzyme at $120 \mathrm{~min}$ did not change the amount of reaction, showing that the kinetic plateau was not due to enzyme inactivation. Two mutant proteins in which D80 had been mutated to $\mathrm{N}$ or $\mathrm{T}$, which were overexpressed and purified in exactly the same way, were completely inactive, even when present in a 10 -fold excess over that of the wild type. This result will be discussed below. RNA incubated with wild-type or mutant TruD for $200 \mathrm{~min}$ (Fig. 3A), and RNA incubated for the same time without TruD were sequenced for $\Psi$. Figure $3 \mathrm{~B}$ shows that the product of the in vitro reaction is $\Psi 13$, just as it is in vivo.

\section{Effect of the absence of TruD and $\Psi 13$ on the cell}

Deletion of truD causes the loss both of the gene product, TruD, and the synthase product, $\Psi 13$. What is the physiological effect of this loss? One excellent parameter for measuring effects on cells is their growth rate when they are dividing at the maximum rate allowed by the growth conditions, that is, in exponential phase. Therefore, growth rates of the wild-type and deletion strains were determined. Cells were grown with aeration in $\mathrm{LB}$ or $\mathrm{M} 9 /$ glucose $/ \mathrm{Mg}$ medium (Gutgsell et al. 2000) at 25,37 , and $42^{\circ} \mathrm{C}$, and

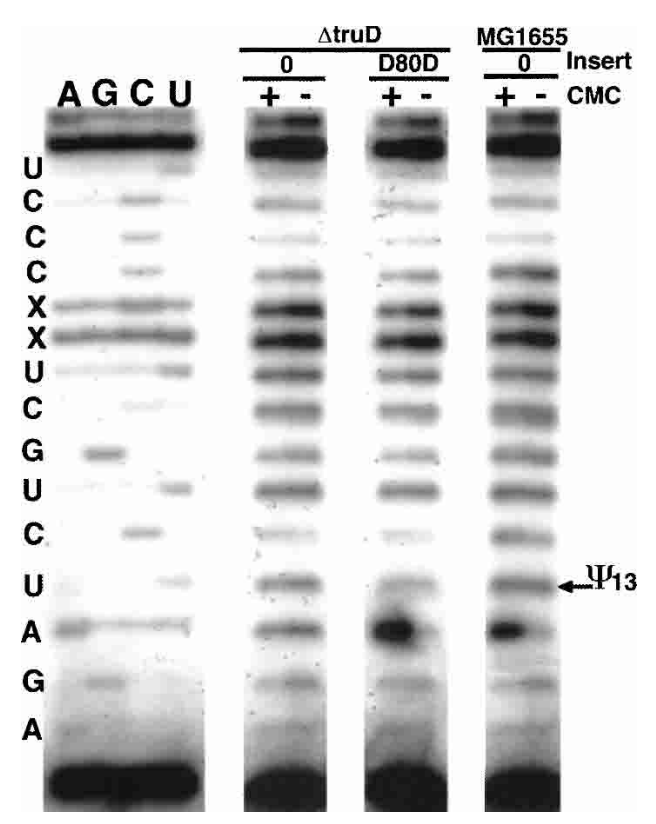

FIGURE 2. $\Psi$ sequence analysis of the truD deletion strain $(\Delta \operatorname{truD})$. Deletion of the $y g b O$ (renamed truD) gene in MG1655, construction of wild-type-containing pTrc99A, transformation, and growth of the transformed cells, isolation of RNA, and $\Psi$ sequencing were all performed as described in Materials and Methods. The primer was complementary to tRNA ${ }^{\text {Glu }}$ residues $17-33$. The $\Delta$ truD strain was transformed with pTrc99A with no insert (0) and with the wild-type truD structural gene (D80D). As a control, wild-type MG1655 was transformed with pTrc99A with no insert (0). Cells at an $\mathrm{A}_{600}$ of 0.6 were induced with $2 \mathrm{mM} \mathrm{IPTG}$ for $3 \mathrm{~h}$ at $37^{\circ} \mathrm{C}$ before phenol extraction of the RNA. Reaction with (+) or without (-) CMC followed the standard sequencing protocol. (A, G, C, U) RNA sequencing lanes. The arrow shows the position of the stop one residue $3^{\prime}$ to $\Psi 13$. 

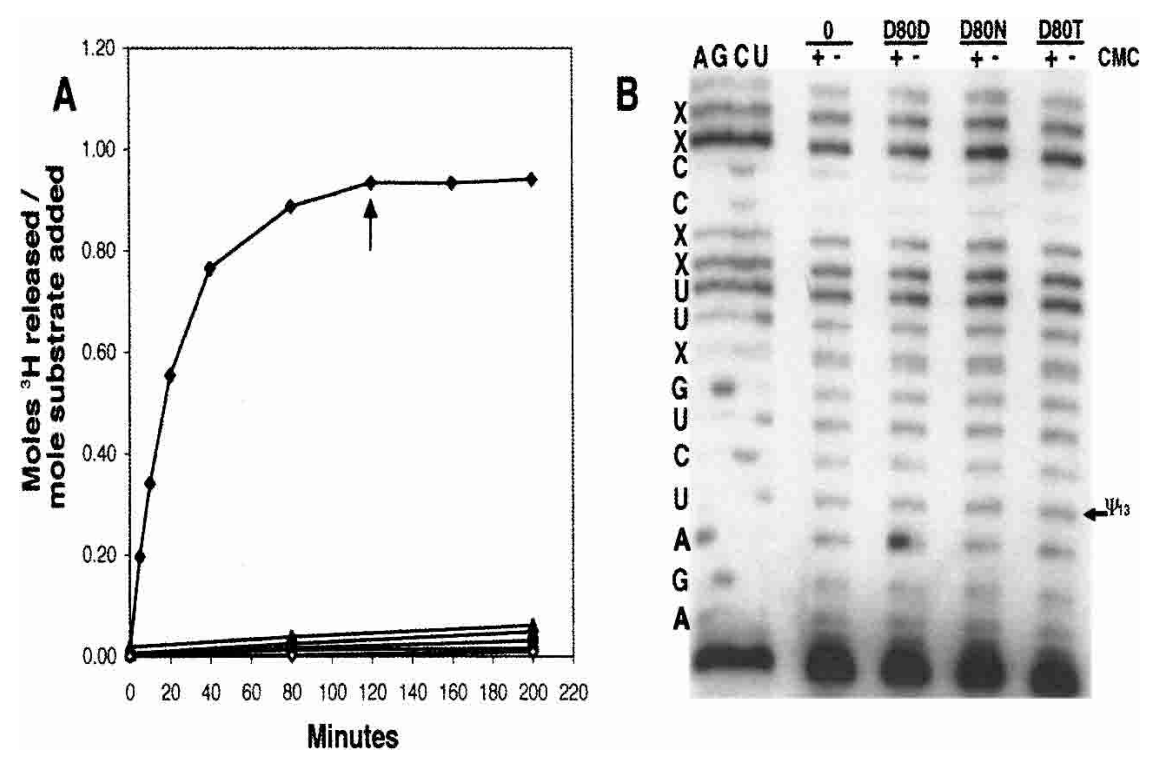

FIGURE 3. In vitro activity of the wild-type (D80D) and two mutant TruD synthases (D80N, D80T). (A) ${ }^{3} \mathrm{H}$ release activity of wild-type and mutant TruD. A $5-\left[{ }^{3} \mathrm{H}\right]$ uracil-containing tRNA ${ }^{\text {Glu }}$ transcript was prepared and pseudouridine formation measured as release of ${ }^{3} \mathrm{H}$ as described in Materials and Methods. Substrate concentration was $100 \mathrm{nM}$ in a reaction volume of $0.1 \mathrm{~mL}$. Wild-type and mutant recombinant synthases were overexpressed from pET28a plasmids and purified (see Materials and Methods). A total of $0.05 \mu \mathrm{g}$ of D80D ( $\bullet$ ), no enzyme $(\diamond)$, and $0.54 \mu \mathrm{g}$ of D80N and D80T (triangles and circles, respectively) were added. A total of $0.15 \mu \mathrm{g}$ of wild-type or mutant enzyme was added to the reaction at $120 \mathrm{~min}$ (arrow). (B) $\Psi$ sequence analysis of the site of in vitro $\Psi$ formation on tRNA ${ }^{\text {Glu }}$. RNAs that had been reacted with the recombinant wild-type and mutant enzyme to completion (200 min) were obtained by phenol extraction of the mixture and analyzed by the sequencing technique described in Materials and Methods. RNA was reacted with (+) or without (-) CMC following the standard sequencing protocol. (A, G, C, U) RNA sequencing lanes. The arrow shows the position of the stop one residue $3^{\prime}$ to $\Psi 13$.

assayed spectrophotometrically at $600 \mathrm{~nm}$ over 3-6 doublings. No difference in growth rate between the two strains was found under any of the conditions. Moreover, growth competition studies, done as described previously (Gutgsell et al. 2000), in LB at 37 or $42^{\circ} \mathrm{C}$ did not show any effect of the deletion (data not shown).

\section{Homologs of TruD are found in other genomes}

The online version of PSI-BLAST (http://www.ncbi.nlm.nih. gov/BLAST/) at the National Center for Biotechnology Information (NCBI) was used to detect homologs of TruD. Initially, the amino acid sequence of TruD was searched against the nonredundant protein database at the NCBI site, and iterated to convergence with the default threshold (0.005). This initial search identified 68 sequences with an E-value better than the threshold ranging from $\mathrm{e}^{-132}$ to $\mathrm{e}^{-8}$, and 16 sequences with E-values above the threshold ranging from 0.027 to 9.3. To expand the number of homologs, the sequences with E-values greater than the default threshold value were individually searched against the database with PSI-BLAST. None of these sequences were able to identify more than a few members of the 68-member list. Therefore, these sequences were excluded from the class.
Subsequent analysis of the class was done by multiple alignment using the Clustal X version 1.81 software program (Jeanmougin et al. 1998). Initially, a phylogenetic tree was created, and using the tree, all members were multiple aligned to each other. Final adjustment of the alignment was made manually. Even though the PSI-BLAST search found statistically significant homology among the 68 members, six of the sequences (gi|20343688), gi|9506681|, gi|14250243|, gi|20823027|, gi|9366673|, and gi|20957799|) did not align at the amino terminus. Therefore, these members were excluded in the final alignment. Although it is possible that these proteins were incomplete in the database, we did not attempt to identify the missing sequence in the corresponding genome to verify this. Additionally, three pairs of sequences were found to be identical or nearly so. Two proteins (gi|16554460| and gi|10579883|) from Halobacterium sp. NRC-1 are the products of the same gene, VNG0243C, but one (gi|10579883|) is 141 amino acids longer at the amino terminus. Two proteins (gi|16130652| and gi|15803262|) from E. coli (strain K-12 and EDL933, respectively) differed in two amino acids at residues 176 (Gln versus Leu) and 242 (Ala versus Val), respectively. Two proteins (gi|16761700| and gi|16766234|) were from different subgroups of Salmonella (enterica serovar Typhi and typhimurium LT2, respectively) and differed only at amino acid residue 61 (Val versus Ala, respectively). One representative of each pair was used in the final alignment of 59 sequences (Fig. 4).

There are 24 TruD homologs in Eubacteria, 19 in Archaea, and 16 are in eukaryotes. All are from complete genome sequences except for the archaeal Ferroplasma acidarmanus and seven from eukaryotes that are from incomplete genome sequences. Even early diverging organisms such as Aquifex aeolicus of the Eubacteria, Encephalitozoon cuniculi of the Eukarya, and all of the sequenced Archaea have a TruD homolog, suggesting that like the canonical $\Psi$ synthases, this new class has ancient origins. Although all of the analyzed Archaea have a TruD homolog, as do all of the sequenced eukaryotes except Guillardia theta, homologs in the Eubacteria were found mainly in the $\gamma$ and $\delta-\varepsilon$ subdivisions of the Proteobacteria. However, homologs were found in A. aeolicus and Deinococcus radiodurans, two organisms among the earliest to branch off in the bacterial kingdom. Therefore, the absence of TruD homologs from major branches of the Eubacteria sug- 
gests that they were evolutionarily lost rather than never present.

Six motifs were detected, as shown in Figure 4. Beside these motifs, regions showing some homology were found in amino-terminal neighboring residues of motif II, between motifs IV and V, and between motifs V and VI. Motif I is missing in five organisms, motif $\mathrm{V}$ in one, and motif VI is absent in two. Of the 10 completely conserved amino acids, 4 are found in motif II, and 3 are in the sequence, GXKD, which also contains the only completely conserved aspartate. Analysis of this motif is discussed below.

\section{Aspartate 80 in the GXKD motif of TruD is essential for $\Psi$-forming activity}

The multiple sequence alignment of Figure 4 identified 10 completely conserved amino acids, 3 of which are in the motif GXKD. Because aspartate is an essential residue in all other known $\Psi$ synthases (Ofengand and Rudd 2000; Ofengand et al. 2001b), and may be the catalytic residue ( $\mathrm{Gu}$ et al. 1999; Hoang and Ferré-D’Amaré 2001), we postulated that the aspartate in the GXKD motif, D80, which is the only completely conserved aspartate in all of the motifs, might be essential for activity. This was tested in vitro by constructing the appropriate mutant gene in pET28a and overexpressing the protein with an amino-terminal His tag for affinity purification in the same way as for the wild type. Figure 3 shows that in vitro, both D80T and D80N mutant TruD were completely inactive, even when a large excess of protein was added. Clearly, D80 is essential for $\Psi$ activity. We suggest that D80 may be the catalytic aspartate in TruD, and that when the three-dimensional structure of this protein is determined, D80 will be found at the equivalent location in space and with a similar protein fold as the catalytic aspartate and surrounding protein fold in the other three known structures (Mueller 2002).

\section{DISCUSSION}

\section{Specificity of the $E$. coli tRNA $\Psi 13$ synthase}

The characterization of this synthase accounts for the last known site for $\Psi$ in E. coli rRNA or tRNA. The 10 previously identified synthases accounted for all of the other sites (Del Campo et al. 2001). In vivo, it is the only synthase capable of making this $\Psi$, as deletion of the truD gene caused $\Psi 13$ to disappear and restoration of the gene on a plasmid caused it to reappear. Likewise, TruD must be unable to make $\Psi$ at any of the other known in vivo sites in tRNA or rRNA, as deletion of the appropriate synthase gene causes loss of its $\Psi$ while in the continued presence of truD. However, whether any of the various small RNAs in E. coli (Argaman et al. 2001; Rivas et al. 2001; Wassarman et al. 2001) contain $\Psi$, and whether any are made by this synthase, is still an open question.

\section{Function of $\Psi 13$ in tRNA}

No growth effect was detected upon deletion of $\operatorname{truD}$, either in exponential growth rate at temperatures from 25 to $-42^{\circ} \mathrm{C}$ in rich or minimal medium, or in competition with wild type in rich medium at 37 or $42^{\circ} \mathrm{C}$. Nevertheless, considering the wide distribution of $\Psi 13$ in tRNA (see below), its location at the end of a base-paired stem connected by a loop, and the known propensity of $\Psi$ for structural stabilization (Meroueh et al. 2000; Newby and Greenbaum 2002, and references therein), it might be that certain tRNAs, like E. coli tRNA ${ }^{\text {Glu }}$, require this particular stabilization. Analysis of the database of sequenced tRNAs (Sprinzl and Vassilenko 2002) reveals a suggestive relationship between the distribution of $U$ or $\Psi$ at position 13 and the nature of the putatively base-paired residue at position 22. Excluding only animal mitochondrial tRNAs, when U22 is present, $\Psi$ is found in 45 of $47(96 \%)$ of the cases. With G22, $\Psi$ is present in 32 of $45(71 \%)$ of the tRNAs, and with A22, $\Psi$ is only found in 8 of $32(25 \%)$ examples. Thus, $\Psi$ appears needed when the opposite partner is $U$, is somewhat preferred when making the G.U wobble pair, and is actually not preferred for making an A-U base pair. This may explain why the lack of $\Psi 13$ in E. coli, which has $\Psi 13$ in only one tRNA, tRNA ${ }^{\text {Glu }}$, and even that one is opposite G22, has no detectable growth effect. In this case, it may be that the effect only becomes manifest under special conditions, when $\mathrm{tRNA}^{\mathrm{Glu}}$ might become limiting for some metabolic process. In other organisms, like Saccharomyces cerevisiae, which has five tRNAs with a $\Psi 13: \mathrm{U} 22$ base pair, deletion of the $\Psi 13$ synthase gene might have a detectable growth defect even under laboratory growth conditions.

\section{Prevalence of $\Psi 13$ and $\Psi 13$ synthases}

Although only tRNA $^{\text {Glu }}$ contains $\Psi 13$ in E. coli, $\Psi 13$ is actually widely distributed both among tRNAs and species. tRNAs for 16 of the 21 (including Met $_{\mathrm{i}}$ ) amino acids have $\Psi 13$, and it is found in tRNAs from all three major phyla of life, the Eubacteria, Archaea, and Eukarya (Sprinzl and Vassilenko 2002). Presumably, all of these organisms have a $\Psi$ synthase for making $\Psi 13$. In fact, a partially purified enzyme specific for $\Psi 13$ in S. cerevisiae has been described (Samuelsson and Olsson 1990). However, there is no information available on whether a conventional $\Psi$ synthase, that is, a member of the TruA, TruB, RsuA, or RluA families (Ofengand and Rudd 2000; Ofengand et al. 2001b), or one homologous to TruD is used. There is one homolog of TruD in S. cerevisiae, gi6324817 (YOR243c), see Figure 4, which could be the $\Psi 13$ synthase. However, that gene was shown recently to make a synthase responsible for $\Psi 35$ in yeast U2 snRNA (Ma et al. 2003). Thus, unless this synthase is a dual specificity protein like E. coli RluA (Wrzesinski et al. 1995b) or yeast Pus1p (Massenet et al. 1999), there must still be another sequence class of $\Psi$ synthase in yeast that is responsible for tRNA $\Psi 13$. 


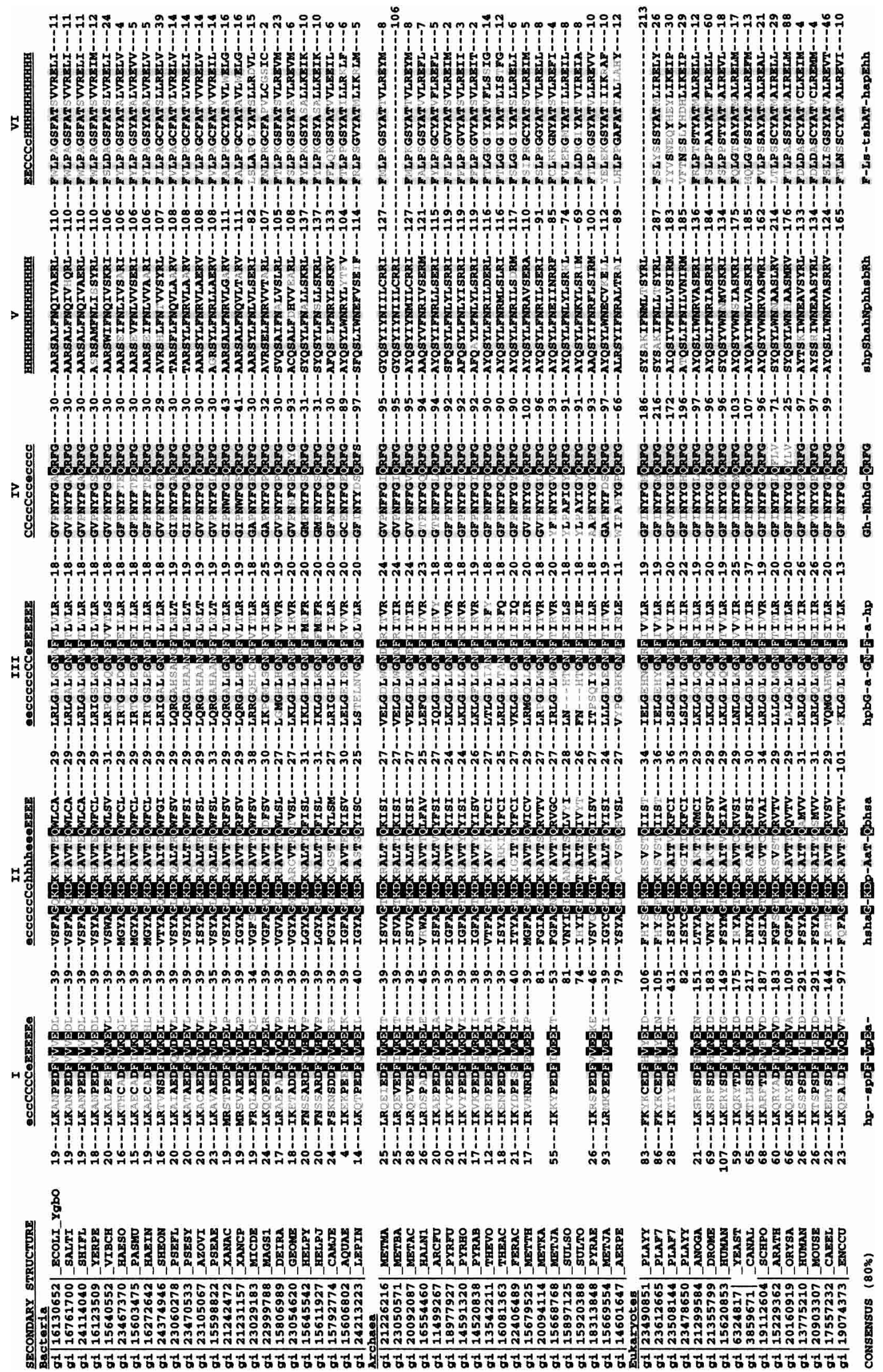




\section{A new class of $\Psi$ synthase}

Identification of $y g b O$ as $t r u D$, the gene for a $\Psi$ synthase with no amino acid sequence homology to the four known classes, TruA, TruB, RsuA, and RluA, provides a potential solution to the problem of too few $\Psi$ synthases in the archaea. Analysis of 16 archaeal genomes for conventional $\Psi$ synthases (Ofengand 2002; J. Ofengand, unpubl.) has shown that the 4 crenarchaeota have but one synthase, which is of the yeast Cbf5 type. This type of synthase works normally with guide RNAs to make $\Psi$ in rRNA (Kiss 2001) and is not known to recognize tRNA. The 12 euryarchaeota have, in addition to the Cbf5-like synthase, a single TruA class enzyme. This class makes $\Psi$ in the tRNA anticodon at residues 38-40 in E. coli (Kammen et al. 1988), yeast (Lecointe et al. 1998), and mouse (Chen and Patton 2000), but is not known to make any other tRNA $\Psi$. However, known archaeal tRNAs have $\Psi$ at eight positions, needing at least four synthases by conventional specificity criteria. Moreover, $\Psi 55$ occurs in Methanothermobacter thermoautotrophicus, Thermoplasma acidophilum, Pyrococcus furiosus, $\mathrm{Ha}$ lobacterium cutirubrum, Haloferax volcanii, and Halococcus morrhua (references cited in Gutgsell et al. 2000), yet the former three lack a recognizable TruB class synthase. This may be true for the latter three as well, but the genome sequencing data is not available. Eighteen archaeal genomes have homologs of TruD (Fig. 4), including M. thermoautotrophicus, T. acidophilum, and P. furiosus, suggesting that some may be responsible for $\Psi 55$ synthesis rather than for $\Psi 13$. Similarly, three eubacteria, Helicobacter pylori, Mycoplasma genitalium, and Mycoplasma pneumoniae, and one eukaryote, Caenorhabditis elegans, lack a putative TruB synthase for making $\Psi 55$ (Ofengand 2002). Two of the four, $H$. pylori and C. elegans, have TruD homologs (Fig. 4). On the other hand, $H$. volcanii, $H$. cutirubrum, $M$. thermoautotrophicus, T. acidophilum, and H. morrhua are known to have tRNAs with $\Psi 13$, so that it is also possible that the TruD homologs found in archaea make $\Psi 13$. In that event, $\Psi 55$ might be made by a synthase of a still different amino acid sequence class. As mentioned above, the yeast $\Psi 13$ synthase might be a member of such an additional class also, as there was only one TruD homolog in yeast, and that was the synthase for U2 snRNA $\Psi 35$. It is also worth noting that whereas E. coli has TruD, it has no other genes homologous to it.

It is still too soon to make firm conclusions about the number of $\Psi$ synthase classes and how they are related. However, the discovery of TruD makes it clear that additional classes could exist. Thus, the current work vastly expands the potential for discovering still more classes of pseudouridine synthases. This discovery also reinforces the fact that, whereas bioinformatic analysis is a very powerful tool for discovery of the function of genes, traditional biochemistry still has an important role to play.

\section{Functional motifs}

The only motif with a conserved aspartate residue is motif II (Fig. 4). The lack of in vitro activity of TruD with this aspartate mutated to asparagine or threonine (Fig. 3) suggests that this motif may be at the catalytic center of this new family of $\Psi$ synthases, as is aspartate in a different sequence context in the conventional $\Psi$ synthases. Alternatively, however, the mutations could have blocked the binding of the mutant synthases to their substrate tRNA rather than affecting the catalytic center. Further studies are needed.

To detect any known RNA-binding motifs, TruD was searched against the Fold Library SCOP version 1.53 (Kelley et al. 2000) at the 3D-PSSM server (http://www.sbg.bio.ic. ac.uk/ 3dpssm/) and with the three-dimensional modelbuilding program 3D-JIGSAW (Contreras-Moreira and Bates 2002), (http://www.bmm.icnet.uk/ 3djigsaw/). These searches did not identify any structural motifs at $\mathrm{E}$ values $<0.05$. The Conserved Orthologous Group (COG) database (http://ncbi.nlm.nih.gov/COG) was also searched using TruD as the query. A subgroup, COG0585, was identified, which contained TruD and 21 other proteins. All were members of the group in Figure 4. However, no experimental data exists for the members (except for TruD) nor do they exhibit any predicted features. Additionally, a PSIBLAST search that reached convergence at iteration 4 failed to detect any proteins with the predicted RNA-binding domains S4, PUA, THUMP, or TRAM. These domains are found in various 4 -thiouridine and pseudouridine synthases

FIGURE 4. Sequence alignment of TruD homologs from other genomes. The alignment was constructed as described in the text. The identity of each homolog is given by the gi number followed by the organism code taken from the Swiss-Prot site (http//:www.expasy.org/cgi-bin/speclist), except that MICDE is Microbulbifer degradans 2-40; MAGS1 is Magnetococcus sp. MC-1; PLAYY is Plasmodium yoelii yoelii. There are six motifs numbered from the amino terminus to the carboxyl terminus as I to VI. The numbers between motifs II and VI are the number of amino acid residues between each motif. The numbers to the left of motif I are the number of residues to the amino terminus. Those to the right of motif VI are the number to the carboxyl terminus. Amino acids conserved $100 \%$ are white on black, amino acids with a $>80 \%$ consensus are black on gray. If there is no single amino acid residue with a $>80 \%$ consensus, amino acids are classified as polar (p: KRHDEQNST), hydrophopic (h: ALICVMYFW) or aliphatic as a subset of hydrophopic (a: ALICVM) as shown in the CONSENSUS line. If any column is not $\mathrm{p}$, h, or a with a $>80 \%$ consensus, then the column is classified according to side-chain size as tiny as a subset of small (t: GAS), small (s: GASCDNPSTV), or big (b: QERKYMFWLI). Residues that fit into a column classification are shown in black. Those that do not fit into the classification of its corresponding column are shown in gray. The secondary structure at the top of the alignment is the output of the secondary structure prediction program PHD (Rost and Sander 1993, 1994) using TruD as the query with (e) $\beta$-trand, (c) coil, and (h) helix. The most confident structure predictions ( $>82 \%$ accuracy) are shown in uppercase letters. The consensus sequence and a summary of the motifs are shown below the alignment. 
and RNA methylases (Aravind and Koonin 1999, 2001; Anantharaman et al. 2001). Likewise, none were found with KH (Siomi et al. 1993) or RRM (Birney et al. 1993) RNAbinding motifs. Rather, all members of the TruD family made a closed set of a new protein group with no function predicted or identified for any one of its members. No members of the PsuX or PsuY families, two groups of proteins distantly related to the TruB family (Watanabe and Gray 2000), were found in the TruD set of Figure 4 either. This suggests that this new family should have a different type of RNA-binding motif than described heretofore.

On the other hand, a common feature of many RNAbase-modifying enzymes is the fusion of specific RNA-binding domains to the respective catalytic domains (Aravind and Koonin 1999). For example, many thiouridine and pseudouridine synthases and RNA methylases share a common domain that is predicted to be an RNA-binding domain (Aravind and Koonin 1999, 2001; Anantharaman et al. 2001). Binding and catalytic domains can be two separate functions in an RNA base-modifying protein molecule. One would identify the target RNA and the other would modify the base to a specific form, but both of the domains would be required for RNA base-modifying enzymes to function properly. Thus, it is possible that the RNA-binding domains of the members of the TruD family are sufficiently different from each other that alignment at their RNA-binding domains fails.

\section{MATERIALS AND METHODS}

\section{Strains}

MG1655 was the wild-type E. coli strain. MG1655 truB::kan (Gutgsell et al. 2000) was used to make the cell extract for purification of the $\Psi 13$ synthase. NovaBlue (Novagen) was the host in all initial transformation experiments. BL21(DE3) (Novagen) was used for overexpression of recombinant TruD protein.

\section{Materials}

5- $\left[{ }^{3} \mathrm{H}\right]$ UTP $(15.3 \mathrm{Ci} / \mathrm{mmole})$ was from Amersham. $\gamma$ - $\left[{ }^{32} \mathrm{P}\right]$ ATP (3000 Ci/mmole) was from Perkin Elmer. Restriction enzymes were from New England Biolabs. Other reagents were obtained as noted.

\section{Buffers}

Buffer A is $10 \mathrm{mM}$ Hepes ( $\mathrm{pH} 8.0$ ), $10 \mathrm{mM} \mathrm{MgCl}_{2}, 5 \mathrm{mM}$ mercaptoethanol, and $0.1 \mathrm{mM}$ EDTA. Buffer B is $20 \mathrm{mM}$ Hepes $(\mathrm{pH}$ 8.0), $20 \mathrm{mM} \mathrm{NH}_{4} \mathrm{Cl}, 5 \mathrm{mM}$ mercaptoethanol, $0.1 \mathrm{mM}$ EDTA, and $10 \%$ glycerol. Buffer $\mathrm{C}$ is buffer $\mathrm{B}$, but at $\mathrm{pH}$ 7.8. Buffer LB is 50 $\mathrm{mM}$ Tris- $\mathrm{HCl}$ (pH 6.8), 100 mM DTT, 2\% SDS, 10\% glycerol, and $0.1 \%$ bromophenol blue.

\section{Pseudouridine formation assay}

Reactions contained $50 \mathrm{mM}$ HEPES ( $\mathrm{pH}$ 7.5), $100 \mathrm{mM} \mathrm{NH}_{4} \mathrm{Cl}, 5$

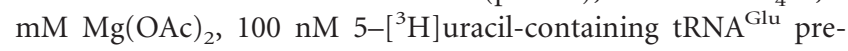

pared by in vitro transcription, $5 \mathrm{mM}$ DTT, 400 units/mL RNasin (Promega), and enzyme or extract. Incubation was at $37^{\circ} \mathrm{C}$. Reactions were stopped by addition of $100 \mu \mathrm{L}$ aliquots to $1.0 \mathrm{~mL}$ of $12 \%$ acid-washed Norit A (Sigma, cat. no. C-4386) in $0.1 \mathrm{~N} \mathrm{HCl}$. Samples were mixed and allowed to stand at room temperature for $5 \mathrm{~min}$ and then centrifuged to remove the charcoal, and the supernatant was passed through a PTFE filter assembly $(0.2 \mu \mathrm{m}$, cat. no. 187 1320, Nalge Nunc International). The charcoal pellet was washed two times with 1.0 and $0.5 \mathrm{~mL}$ of $0.1 \mathrm{~N} \mathrm{HCl}$, each time passing the supernatant wash through the same filter assembly. The washes and supernatant were combined and counted. The value at 0 time without enzyme was subtracted from all samples. One unit of activity is that amount of enzyme catalyzing the release of 1 pmole of ${ }^{3} \mathrm{H}$ to the supernatant in $30 \mathrm{~min}$ at $37^{\circ} \mathrm{C}$.

\section{Plasmids}

The truD gene was PCR amplified from MG1655 genomic DNA using pfu turbo polymerase (Stratagene) and cloned into the NcoI and BamHI sites of pTrc99A (Pharmacia) and the NdeI and BamHI sites of pET28a (Novagen). The carboxy-terminal primer (5'-CAGGATCCCTTTGCGCAGCGTTTGTATACCG-3') was the same for insertion of the gene in both plasmids, and incorporated a BamHI site (italics) followed by the complement of residues 43-21 (numbering begins after the TAA stop codon). The aminoterminal primer for cloning into pTrc99A was $5^{\prime}$-CTCGGTCTC GCATGATTGAGTTTGATAATCTCACTTACCTC-3', incorporating a $B s a$ I site (italics) two nucleotides before the AUG start codon (underlined). The amino-terminal primer for cloning into pET28a was 5'-CCACTGGCCATATGATTGAGTTTGATAATC TCACTTACCT-3', incorporating an NdeI site (italics) spanning the AUG start codon (underlined).

D80T and D80N mutants of truD were made in pET28a using the Quick-change XL site-directed mutagenesis kit (Stratagene) according to the instruction manual provided. For $\operatorname{truD}(\mathrm{D} 80 \mathrm{~T})$ and $\operatorname{truD}(\mathrm{D} 80 \mathrm{~N})$, the mutagenic primers were $5^{\prime}$-CAGCTTCGC TGGGCAAAAAACCAAACATGCTGTTACGG-3', and 5'-CAG CTTCGCTGGGCAAAAAAACAAACATGCTGTTACGG-3', respectively. Each mutagenic primer incorporated base changes (underlined in the primer sequence) necessary to mutate the desired aspartate residue. All of the mutant plasmids were verified by DNA sequencing.

pUCt7a and pUCt7b vectors were created by cloning a 41nucleotide long dsDNA fragment into the SmaI site of pUC19 (New England Biolabs, Inc.). The dsDNA fragment (5'pTAATACGACTCACTATAGGAA ${ }^{\downarrow}$ ATGTCTTCAGGGATCTGC $A C-3^{\prime}$ ) contained a T7 promoter (underlined) and recognition sites (italics) for BbsI and BsgI restriction enzymes, respectively. The top strand (shown) and the complementary strand were obtained from Invitrogen with $5^{\prime}$ phosphate ends. These oligomers were annealed to each other in a 1:1 molar ratio prior to bluntend cloning into pUC19 at the SmaI site. The direction of cloning was determined by DNA sequencing. When the insert as written was in the same direction as pUC19 numbering, it was named pUCt7a. Inserts in the opposite direction were named pUCt7b. The plasmids were then cleaved (arrow) with BsgI. The resulting 2-nucleotide 3' overhang (shown in bold) was removed with DNA polymerase I Klenow fragment (New England Biolabs, Inc.) and dephosphorylated with shrimp alkaline phosphatase (Roche Applied Sciences). These linearized plasmids can be used as blunt-end 
acceptor vectors to clone any desired DNA fragment for transcription by $\mathrm{T} 7$ polymerase with two extra $\mathrm{G}$ residues at the $5^{\prime}$ end using cleavage at the BbsI site for runoff transcription. Plasmid pUCt7a was used for tRNA ${ }^{\text {Glu }}$ transcription. The gene was PCR amplified from MG1655 genomic DNA using pfu turbo polymerase. The $5^{\prime}$ primer $\left(5^{\prime}\right.$-pTCCCCTTCGTCTAGAGGCCC- $\left.3^{\prime}\right)$ was the sequence of residues $2-21$ and contained a $5^{\prime}$ phosphate. The $3^{\prime}$ primer ( $5^{\prime}$-pTGGCGTCCCCTAGGGGATTC-3') was the complement of residues 76-57 and also contained a $5^{\prime}$ phosphate. The direction of cloning was tested by DNA sequencing. The plasmid containing the insert in the correct direction was named pUCt7a::tRNAglu.

\section{RNA transcripts}

The tRNA $^{\text {Glu }}$ transcript was prepared by linearization of pUCt7a::tRNA Glu with restriction enzyme BbsI, and transcribed using the T7-MEGAshortscript kit (Ambion). The reaction contained $7.5 \mathrm{mM}$ each of ATP, CTP, UTP, and GTP, $200 \mathrm{nM}$ of plasmid, $800 \mu \mathrm{Ci} / \mathrm{mL}$ 5-[ $\left.{ }^{3} \mathrm{H}\right] \mathrm{UTP}, 2 \mu \mathrm{L}$ T7-MEGAshortscript enzyme mix and $2 \mu \mathrm{L}$ of the $10 \times$ transcription buffer from the Ambion kit in a final volume of $20 \mu \mathrm{L}$. Incubation was at $37^{\circ} \mathrm{C}$ for 10-12 h. The template plasmid was removed by addition of RNase-free DNase to a concentration of 100 units $/ \mathrm{mL}$ at $37^{\circ} \mathrm{C}$ for $20 \mathrm{~min}$. RNA transcripts were then purified by phenol extraction, ethanol precipitation, and G-50 gel filtration.

\section{Purification of the $\Psi 13$ synthase}

Forty grams of E. coli MG1655:: $\Delta$ truB frozen cell pellet, harvested in midlog phase, was thawed at $4^{\circ} \mathrm{C}$ with $30 \mathrm{~mL}$ of buffer A. After removal of liquid by centrifugation, the cells were suspended in 80 $\mathrm{mL}$ of buffer A, 10\% glycerol, $0.67 \mathrm{mM}$ PMSF (Sigma), plus eight tablets of protease inhibitor (Complete, Mini from Roche Applied Science), and passed through a French press at 18,000 psi. (1240 bar). Ribosomes and cell debris were removed by centrifugation at $45,000 \mathrm{rpm}$ for $2 \mathrm{~h}$ in a Ti60 rotor at $4^{\circ} \mathrm{C}$. To the supernatant (S200) was added one-seventh volume of $20 \%$ streptomycin sulfate adjusted to $\mathrm{pH} \mathrm{7.5}$, and the mixture stirred at $4^{\circ} \mathrm{C}$ for $30 \mathrm{~min}$. The streptomycin supernatant $(78 \mathrm{~mL})$ was recovered by centrifugation and precipitated with solid ammonium sulfate $(43.6 \mathrm{~g})$. The mixture was adjusted to $\mathrm{pH} 7.5$ with $\mathrm{NH}_{4} \mathrm{OH}$ and stirred overnight at $4^{\circ} \mathrm{C}$. The precipitate was collected by centrifugation, dissolved in $20 \mathrm{~mL}$ of buffer $\mathrm{B}$, and dialyzed against the same buffer to remove ammonium sulfate.

The dialyzed sample was loaded at $0.5 \mathrm{~mL} / \mathrm{min}$ on a $1.5 \times 45-\mathrm{cm}$ column of DEAE Sepharose CL6B (Pharmacia) equilibrated with buffer $\mathrm{C}$ and eluted with a linear gradient of $1 \mathrm{mM} / \mathrm{mL} \mathrm{NH}_{4} \mathrm{Cl}$ in buffer C. Synthase activity eluted in one major peak at $250 \mathrm{mM}$ $\mathrm{NH}_{4} \mathrm{Cl}$. Peak fractions were pooled, changed, and concentrated by dialysis against buffer C plus $10 \%$ polyethylene glycol 8000 (Sigma). The activity recovered was $80 \%$ of the column input. The sample $(10 \mathrm{~mL})$ was then loaded on an $8-\mathrm{mL}$ MonoS (Pharmacia) column equilibrated in buffer $\mathrm{C}$ and eluted at $1 \mathrm{~mL} / \mathrm{min}$ with a linear gradient of $3.33 \mathrm{mM} \mathrm{NaCl}$ in buffer $\mathrm{C}$. The enzyme eluted as a single peak of activity (Fig. 1) at $250 \mathrm{mM} \mathrm{NaCl}$ with a recovery of $70 \%$ of the input activity. Pooled samples were concentrated, dialyzed against buffer C plus $10 \%$ polyethylene glycol 6000 , glycerol was added to $50 \%$ final concentration, and the samples were stored at $-20^{\circ} \mathrm{C}$.

\section{Deletion strains}

MG1655 truD::kan was constructed by a modification of the gene replacement method of Datsenko and Wanner (2000). A deletion allele containing the amino- and carboxy-terminal fragments of truD linked to a kanamycin resistance cassette was constructed by PCR amplification from plasmid pUC4K (Amersham). The $5^{\prime}$ primer (5'-GCGGTGGCGCTACTCATTAAGGCAACA AAATGATTGAGGATTACGAATTCCCCGGATC- $3^{\prime}$ ) was the truD sequence of residues -29 to +9 (uppercase), in which the $\mathrm{A}$ of the initiating AUG (italics) is +1 followed by the complement of residues $1689-1670$ of pUC4K (underlined). The 3' primer (5' -CCATTCGCCACTGCCTGGCAATGCGGCGGTTATCATCC AATTCTGATTAGAAAAACTCATC- $3^{\prime}$ ) was the complement of truD residues +795 to +759 (uppercase and the first $C$ residue underlined), followed by the sequence of residues 710-731 of pUC4K (underlined). After PCR amplification of the allele, the wild-type truD gene was replaced with the deletion allele as described (Datsenko and Wanner 2000).

\section{Backcross of $\Delta$ truD to wild type by P1-mediated transduction}

Backcrosses mediated by bacteriophage P1 were performed according to Davis et al (1980). For preparation of P1 lysate, $50 \mu \mathrm{L}$ of a fresh overnight culture of the $\Delta$ truD strain was diluted in $5 \mathrm{~mL}$ of $\mathrm{LB}, 0.2 \%$ glucose, $25 \mathrm{mM} \mathrm{CaCl}_{2}$, and grown for $30 \mathrm{~min}$ at $37^{\circ} \mathrm{C}$. After addition of bacteriophage P1 to a final concentration of $1 \times$ $10^{7}$ plaque forming units/milliliters, the cultures were grown for an additional $4 \mathrm{~h}$. Cell debris was removed by centrifugation, 100 $\mu \mathrm{L}$ of chloroform was added to the supernatant, and the mixture stored at $4^{\circ} \mathrm{C}$. For P1-mediated transductional backcross, $100 \mu \mathrm{L}$ of a fresh overnight culture of E. coli MG1655 was added to $5 \mathrm{~mL}$ of $\mathrm{LB}$ and grown to an $\mathrm{A}_{600}$ of $\sim 0.3$ at $37^{\circ} \mathrm{C}$. Cells were harvested by centrifugation and resuspended in $2.5 \mathrm{~mL}$ of $5 \mathrm{mM} \mathrm{CaCl}_{2}, 10$ $\mathrm{mM} \mathrm{MgSO}_{4}$. A total of $100 \mu \mathrm{L}$ of $\mathrm{P} 1$ lysate was added to an equal volume of the cells, and incubated at $30^{\circ} \mathrm{C}$ for $30 \mathrm{~min}$. After adding $150 \mu \mathrm{L}$ of $1 \mathrm{M}$ sodium citrate, cells were grown an additional 1.5 $\mathrm{h}$ to allow expression of drug resistance. The cells were then plated on LB plus $0.04 \mathrm{mg} / \mathrm{mL}$ kanamycin plates. Cotransduction frequency was converted to kilobase by the $\mathrm{Wu}$ formula (Bachman et al. 1976).

\section{Overexpression of TruD and affinity purification}

A total of $0.2 \mathrm{~mL}$ of overnight cultures of BL21(DE3) cells with appropriate pET28a constructs; pET28a::truD(D80D), pET28a ::truD(D80N), and pET28a::truD(D80T), were diluted in $20 \mathrm{~mL}$ of LB plus $0.04 \mathrm{mg} / \mathrm{mL}$ kanamycin. Cells were grown to an $\mathrm{A}_{600}$ of 0.6 at $37^{\circ} \mathrm{C}$ in a shaker, IPTG was added at a final concentration of $2 \mathrm{mM}$, and cells were induced for $3 \mathrm{~h}$. The cells were harvested by centrifugation at $4^{\circ} \mathrm{C}$ in a Sorvall SS-34 rotor at $10,000 \mathrm{~g}$ for $10 \mathrm{~min}$, resuspended in $5 \mathrm{~mL}$ of ice-cold $1 \mathrm{X}$ Binding Buffer (Novagen pET System Manual, 10th edition), and lysed by passage through a French press at 18,000 psi (1260 bar) four times. Cell debris was removed by centrifugation in a Sorvall SS-34 rotor at $4^{\circ} \mathrm{C}$ at $14,000 \mathrm{~g}$ for $20 \mathrm{~min}$. The post-centrifugation supernatant was filtered through a 0.45 micron syringe-end filter (Nalgene). Wild-type and D80 mutants of TruD were affinity purified using 
His-Bind Quick 900 Cartridges (Novagen) following the protocol of the manufacturer (Novagen TB054, Rev.B., 0602).

\section{Pseudouridine sequencing}

Sequencing of tRNA ${ }^{\mathrm{Glu}}$ with ${ }^{32} \mathrm{P}$ end-labeled primers was done as described (Ofengand et al. 2001a).

\section{Other methods and materials}

SDS gel electrophoresis was performed as described previously (Raychaudhuri et al. 1998). For amino-terminal sequencing of TruD, the protein was transferred from SDS gels as in Figure 1B to a PVDF membrane, and amino-terminal sequencing performed by automated Edman degradation on an Applied Biosystems Model 491 Protein Sequencer (Procise) at the University of Miami Protein Analysis Core Facility. Exponential growth rates and competition studies were done as described previously (Gutgsell et al. 2000). Transformation, growth of transformed cells, and isolation of total RNA were performed as described (Del Campo et al. 2001). Protein was determined by the Bradford assay.

\section{ACKNOWLEDGMENTS}

We thank Professor Kenneth E. Rudd, this department, for many stimulating and helpful discussions about bioinformatics in general and the data of Figure 4 in particular. Supported in part by NIH grant GM58879.

The publication costs of this article were defrayed in part by payment of page charges. This article must therefore be hereby marked "advertisement" in accordance with 18 USC section 1734 solely to indicate this fact.

Received February 5, 2003; accepted February 27, 2003.

\section{REFERENCES}

Aravind, L. and Koonin, E.V. 1999. Novel predicted RNA-binding domains associated with the translation machinery. J. Mol. Evol. 48: $291-301$.

2001. THUMP-a predicted RNA-binding domain shared by 4-thiouridine, pseudouridine synthases and RNA methylases. Trends Biochem. Sci. 26: 215-217.

Anantharaman, V., Koonin, E.V., and Aravind, L. 2001. TRAM, a predicted RNA-binding domain, common to tRNA uracil methylation and adenine thiolation enzymes. FEMS Microbiol. Lett. 19: $215-221$.

Argaman, L., Hershberg, R., Vogel, J., Bejerano, G., Wagner, E.G., Margalit, H., and Altuvia, S. 2001. Novel small RNA-encoding genes in the intergenic regions of Escherichia coli. Curr. Biol. 11: 941-950.

Arluison, V., Hountondji, C., Robert, B., and Grosjean, H. 1998. Transfer RNA-pseudouridine synthetase Pus1 of Saccharomyces cerevisiae contains one atom of zinc essential for its native conformation and tRNA recognition. Biochemistry 37: 7268-7276.

Bachmann, B.J., Low, K.B., and Taylor, A.L. 1976. Recalibrated linkage map of Escherichia coli K-12. Bacteriol. Rev. 40: 116-167.

Birney, E., Kumar, S., and Krainer, A.R. 1993. Analysis of the RNArecognition motif and RS and RGG domains: Conservation in metazoan pre-mRNA splicing factors. Nucleic Acids Res. 21: 58035816.

Chen, J. and Patton, J.R. 1999. Cloning and characterization of a mammalian pseudouridine synthase. RNA 5: 409-419.

- 2000. Pseudouridine synthase 3 from mouse modifies the anticodon loop of tRNA. Biochemistry 39: 12723-12730.

Conrad, J., Sun, D., Englund, N., and Ofengand, J. 1998. The rluC gene of Escherichia coli codes for a pseudouridine synthase which is solely responsible for synthesis of pseudouridine at positions 955, 2504, and 2580 in 23 S ribosomal RNA. J. Biol. Chem. 273: $18562-$ 18566.

Contreras-Moreira, B. and Bates, P.A. 2002. Domain Fishing: A first step in protein comparative modelling. Bioinformatics 18: 11411142.

Cortese, R., Kammen, H.O., Spengler, S.J., and Ames. B.N. 1974. Biosynthesis of pseudouridine in transfer ribonucleic acid. J. Biol. Chem. 249: 1103-1108.

Datsenko, K.A. and Wanner, B.L. 2000. One-step inactivation of chromosomal genes in Escherichia coli K-12 using PCR products. Proc. Natl. Acad. Sci. 97: 6640-6645.

Davis, R.W., Botstein, D., and Roth, J.R. 1980. A manual for genetic engineering: Advanced bacterial genetics Cold Spring Harbor Laboratory, Cold Spring Harbor, NY.

Del Campo, M., Kaya, Y., and Ofengand, J. 2001. Identification and site of action of the remaining four putative pseudouridine synthases in Escherichia coli. RNA 7: 1603-1615.

Foster, P.G., Huang, L., Santi, D.V., and Stroud, R.M. 2000. The structural basis for tRNA recognition and pseudouridine formation by pseudouridine synthase I. Nat. Struct. Biol. 7: 2327.

Gu, X., Liu, Y., and Santi, D.V. 1999. The mechanism of pseudouridine synthase I as deduced from its interaction with 5-fluorouraciltRNA. Proc. Natl. Acad. Sci. 96: 14270-14275.

Gustafsson, C., Reid, R., Greene, P.J., and Santi, D.V. 1996. Identification of new RNA modifying enzymes by iterative genome search using known modifying enzymes as probes. Nucleic Acids Res. 24: 3756-3762.

Gutgsell, N., Englund, N., Niu, L., Kaya, Y., Lane, B.G., and Ofengand, J. 2000. Deletion of the Escherichia coli pseudouridine synthase gene truB blocks formation of pseudouridine 55 in tRNA in vivo, does not affect exponential growth, but confers a strong selective disadvantage in competition with wild-type cells. RNA 6: 18701881.

Hellmuth, K., Grosjean, H., Motorin, Y., Deinert, K., Hurt, E., and Simos, G. 2000. Cloning and characterization of the Schizosaccharomyces pombe tRNA:pseudouridine synthase Pus1p. Nucleic Acids Res. 28: 4604-4610.

Hoang, C. and Ferré-D’Amaré, A.R. 2001. Cocrystal structure of a tRNA Psi55 pseudouridine synthase. Nucleotide flipping by an RNA-modifying enzyme. Cell 107: 929-939.

Huang, L., Ku, J., Pookanjanatavip, M., Gu, X., Wang, D., Greene, P.J., and Santi, D.V. 1998a. Identification of two Escherichia coli pseudouridine synthases that show multisite specificity for 23S RNA. Biochemistry 37: 15951-15957.

Huang, L., Pookanjanatavip, M., Gu, X., and Santi. D.V. 1998b. A conserved aspartate of tRNA pseudouridine synthase is essential for activity and a probable nucleophilic catalyst. Biochemistry 37: $344-351$.

Jeanmougin, F., Thompson, J.D., Gouy, M., Higgins, D.G., and Gibson, T.J. 1998. Multiple sequence alignment with Clustal X. Trends Biochem. Sci. 23: 403-405.

Kammen, H.O., Marvel, C.C., Hardy, L., and Penhoet, E.E. 1988. Purification, structure, and properties of Escherichia coli tRNA pseudouridine synthase I. J. Biol. Chem. 263: 2255-2263.

Kelley, L.A., MacCallum, R.M., and Sternberg, M.J.E. 2000. Enhanced genome annotation using structural profiles in the program 3DPSSM. J. Mol. Biol. 299: 499-520.

Kiss, T. 2001. Small nucleolar RNA-guided post-transcriptional modification of cellular RNAs. EMBO J. 20: 3617-3622. 
Koonin, E.V. 1996. Pseudouridine synthases: Four families of enzymes containing a putative uridine-binding motif also conserved in dUTPases and dCTP deaminases. Nucleic Acids Res. 24: 24112415.

Lecointe, F., Simos, G., Sauer, A., Hurt, E.C., Motorin, Y., and Grosjean, H. 1998. Characterization of yeast protein Deg1 as pseudouridine synthase (Pus3) catalyzing the formation of $\Psi 38$ and $\Psi 39$ in tRNA anticodon loop. J. Biol. Chem. 273: 13161323.

Ma, X., Zhao, X., and Yu, Y.-T. 2003. Pseudouridylation $(\Psi)$ of U2 snRNA in S. cerevisiae is catalyzed by an RNA-independent mechanism. $E M B O J$ J. 22: (in press).

Massenet, S, Motorin, Y., Lafontaine, D.L.J., Hurt, E.C., Grosjean, H., and Branlant, C. 1999. Pseudouridine mapping in the Saccharomyces cerevisae spliceosomal UsnRNAs reveals that pseudouridine synthase Pus1p exhibits a dual substrate specificity for U2 snRNA and tRNA. Mol. Cell Biol. 19: 2142-2154.

Meroueh, M., Grohar, P.J., Qiu, J., SantaLucia Jr., J., Scaringe, S.A., and Chow, C.S. 2000. Unique structural and stabilizing roles for the individual pseudouridine residues in the 1920 region of Escherichia coli 23SrRNA. Nucleic Acids Res. 28: 20752083.

Motorin, Y., Keith, G., Simon, C., Foiret, D., Simos, G., Hurt, E., and Grosjean, H. 1998. The yeast tRNA:pseudouridine synthase Puslp displays a multisite substrate specificity. RNA 4: 856-869.

Mueller, E.G. 2002. Chips off the old block. Nat. Struct. Biol. 9: 320322.

Newby, M.I. and Greenbaum, N.L. 2002. Investigation of Overhauser effects between pseudouridine and water protons in RNA helices. Proc. Natl. Acad. Sci. 99: 12697-12702.

Nurse, K., Wrzesinski, J., Bakin, A., Lane, B.G., and Ofengand, J. 1995. Purification, cloning, and properties of the tRNA $\Psi 55$ synthase from Escherichia coli. RNA 1: 102-112.

Ofengand, J. 2002. Ribosomal RNA pseudouridines and pseudouridine synthases. FEBS Lett. 514: 17-25.

Ofengand, J. and Rudd, K. 2000. The bacterial, archaeal, and organellar ribosomal RNA pseudouridines and methylated nucleosides and their enzymes. In The ribosome: Structure, function, antibiotics, and cellular interactions (eds. R.A. Garrett et al.), pp. 175-189. ASM Press, Washington, DC.

Ofengand, J., Del Campo, M., and Kaya, Y. 2001a. Mapping pseudouridines in RNA molecules. Methods 25: 365-373.

Ofengand, J., Malhotra, A., Remme, J., Gutgsell, N., Del Campo, M., Jean-Charles, S., Peil, L., and Kaya, Y. 2001b. Pseudouridines and pseudouridine synthases of the ribosome. Cold Spring Harbor Symp. Quant. Biol. 66: 147-159.

Raychaudhuri, S., Conrad, J., Hall, B.G., and Ofengand, J. 1998. A pseudouridine synthase required for the formation of two universally conserved pseudouridines in ribosomal RNA is essential for normal growth of Escherichia coli. RNA 4: 1407-1417.

Rivas, E., Klein, R.J., Jones, T.A., and Eddy, S.R. 2001. Computational identification of noncoding RNAs in E. coli by comparative genomics. Curr. Biol. 11: 1369-1373.

Rost, B. and Sander, C. 1993. Prediction of protein structure at better than 70\% accuracy. J. Mol. Biol. 232: 584-599.

- 1994 Combining evolutionary information and neural networks to predict protein secondary structure. Proteins 19: 55-72.

Rozenski, J., Crain, P.F., and McCloskey, J.A. 1999. The RNA modification database: 1999 update. Nucleic Acids Res. 27: 196-197.

Samuelsson, T. and Olsson, M. 1990. Transfer RNA pseudouridine synthases in Saccharomyces cerevisiae. J. Biol. Chem. 265: 87828787.

Siomi, H., Matunis, M.J., Michael, W.M., and Dreyfuss, G. 1993. The pre-mRNA binding K protein contains a novel evolutionarily conserved motif. Nucleic Acids Res. 21: 1193-1198.

Sivaraman, J., Sauvé, V., Larocque, R., Stura, E.A., Schrag, J.D., Cygler, M., and Matte, A. 2002. Structure of the $16 \mathrm{~S}$ rRNA pseudouridine synthase RsuA bound to uracil and UMP. Nat. Struct. Biol. 9: $353-$ 358.

Sprinzl, M. and Vassilenko, K.S. 2002. Compilation of tRNA sequences and sequences of tRNA genes (December 2002). http:// www.uni-bayreuth.de/departments/biochemie/trna/

Wassarman, K.M., Repoila, F., Rosenow, C., Storz, G., and Gottesman, S. 2001. Identification of novel small RNAs using comparative genomics and microarrays. Genes \& Dev. 15: 1637-1651.

Watanabe, Y. and Gray, M.W. 2000. Evolutionary appearance of genes encoding proteins associated with box H/ACA snoRNAs: cbf5p in Euglena gracilis, an early diverging eukaryote, and candidate Garlp and Nop10p homologs in archaebacteria. Nucleic Acids Res. 28: 2342-2352.

Wrzesinski, J., Bakin, A., Nurse, K., Lane, B.G., and Ofengand, J. 1995a. Purification, cloning, and properties of the 16S RNA $\Psi 516$ synthase from Escherichia coli. Biochemistry 34: 8904-8913.

Wrzesinski, J., Nurse, K., Bakin, A., Lane, B.G., and Ofengand, J. 1995b. A dual-specificity pseudouridine synthase: Purification and cloning of a synthase from Escherichia coli which is specific for both $\Psi 746$ in $23 \mathrm{~S}$ RNA and for $\Psi 32$ in tRNAPhe. RNA 1: 4374481 . 

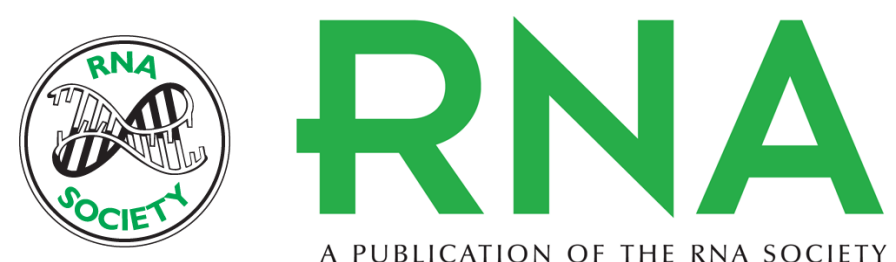

A PUBLICATION OF THE RNA SOCIETY

\section{A novel unanticipated type of pseudouridine synthase with homologs in bacteria, archaea, and eukarya}

YUSUF KAYA and JAMES OFENGAND

RNA 2003 9: 711-721

References This article cites 49 articles, 18 of which can be accessed free at: http://rnajournal.cshlp.org/content/9/6/711.full.html\#ref-list-1

\section{License}

Email Alerting Receive free email alerts when new articles cite this article - sign up in the box at the Service top right corner of the article or click here. 